\title{
Experimental Investigation of Annular Flow Behaviour in Horizontal Pipe
}

\author{
Osokogwu' ${ }^{1}$, Uche $^{1}$ \\ ${ }^{1}$ School of Water, Energy and Environment, \\ Cranfield University, Bedfordshire, MK 43 0AL, UNITED KINGDOM \\ *Corresponding Author
}

DOI: https://doi.org/10.30880/ijie.2021.13.06.014

Received 11 November 2019; Accepted 29 January 2020; Available online 31 August 2021

\begin{abstract}
The experimental investigations of annular flow were conducted in horizontal pipe using water/air in a $0.0504 \mathrm{~m}$ internal diameter pipe loop with a total length of $28.68 \mathrm{~m}$. To understand annular flow behaviors, conductivity ring sensors, conductance probe sensors and Olympia high speed digital camera were used. In all the experiments, emphasis were on annular flow behavior, phase distribution and liquid film thickness. Liquid film thickness was observed to be thicker mostly when the superficial gas velocities were within $8.2699 \mathrm{~m} / \mathrm{s}$ to 12.0675 $\mathrm{m} / \mathrm{s}$. Above the aforementioned superficial gas velocities, the flow became uniformly distributed on the walls of the internal pipe diameter hence reducing the thicker liquid film at the bottom with gas core at the center of the pipe. More so, annular-slug flow was discovered in the investigation. At superficial liquid velocity of $0.0505 \mathrm{~m} / \mathrm{s}-0.1355$ $\mathrm{m} / \mathrm{s}$ on superficial gas velocities of $8.2699 \mathrm{~m} / \mathrm{s}-12.0675 \mathrm{~m} / \mathrm{s}$, annular-slug flow was prominent. Also discovered was at superficial liquid velocities of $0.0903 \mathrm{~m} / \mathrm{s}-0.1355 \mathrm{~m} / \mathrm{s}$ with respect to superficial gas velocities of 13.1692 $\mathrm{m} / \mathrm{s}-23.4575 \mathrm{~m} / \mathrm{s}$, the pipe walls are fully covered with liquid film at very high speed at the entire walls (upper walls and bottom). Also discovered in this experiment is the wavy flow of the upper walls. The liquid film thickness that flows at the upper pipe walls, creeps in a wavy flow. Therefore, the entire flow behavior in an annular flow could be grouped into; wavy-flow at the upper walls, annular-slug flow and thicker liquid film at the bottom with gas core at the center.
\end{abstract}

Keywords: Multiphase flow, annular flow, phase distribution, gas core, high velocity

\section{Introduction}

Multiphase flow in pipes is the act of conveying different fluids in a system like pipes to its destination. It involves different phases of fluids travelling either at different velocities or same velocity to their delivery point. As hydrocarbon fluid leaves the reservoir, there are pressure losses along the vertical tubing and the horizontal flowlines which often creates the different flow patterns in the pipes before the delivery point, depending on the well, pipe geometry and the dominant phase in the fluid flow. The major flow patterns are; bubble, slug, stratified, plug, annular and mist flows. In this study, annular flow in horizontal pipe is the focus. Annular flow is encountered both at the upstream and downstream on a typical gas well tubing and pipeline respectively. Also in a gas dominated phase flow in an oil well or gas transmission pipelines because of condensation. It also occurs in the nuclear power industries, refining/chemical manufacturing industries that depend more on heat exchangers, reactors and several two-phase flow systems user.

Annular flow is a flow condition in multiphase where the liquid and the gas flows together in the pipe but with the gas dominant and flows at high velocity. In horizontal pipes, the flow goes with high gas velocity at the core of the pipe with severe impact of circumferential liquid films at the walls of the internal pipe which were acted upon by 
gravity as drains to the bottom of the pipe, [1]. As noted by Sergey et al., [2] the liquid film thickness flows along pipe walls under the actions of gravity and shear stress induced by high-velocity gas at the core of the pipe. The phase distribution of fluid in annular flow consists of slow liquid film on the pipe walls with more flowing gas core at the center of the pipes, containing liquid droplets. However, there is no absolute uniform liquid film thickness across the walls of the internal pipe.

Annular flow, reveals a typical thick liquid film at the bottom of the internal horizontal pipe that travels at low pace than the gas phase, Kesana et al., [3]. The joint forces of the slow flow of the liquid at the bottom and the fast gas phase aids in increasing the wall shear stress and pressure gradient in annular flow. It is of interest to note that a thin liquid film exists at the upper walls of the internal diameter of the horizontal pipes in annular flow.

Kesana et al., [3] worked on particle size and viscosity effect on erosion in annular and slug flow regime on a horizontal 3-inch $(0.0762 \mathrm{~m})$ diameter pipe. They observed in their experiment a typical flow which was called annular-slug flow (pseudo slug flow). They noted that the flow occurs at higher superficial gas velocity greater than slug flow situations, which was a transition between annular and slug flow, Kesana et al., [3]. Again, the liquid film thickness is not uniform at the cross-sectional areas of the pipe and indeed much thicker at the bottom of the pipe, Kesana et al., [3].

Liang et al., [4] conducted experiment on phase separation of gas-liquid flow using a 40mm pipe internal diameter with a small break of $2.5 \mathrm{~mm}$ at different angles. They observed that the splitting characteristic of slug is far different from that of annular and wavy flow. They noted that the effect of gas velocity on phase split under annular and wavy flows at angle 00 depicts that fraction of liquid increases when taken off increases with gas superficial velocity. The liquid film creeps up the pipe walls with increase in gas velocity, Zhang et al.,[5], which may turn into semi-annular and much later to a uniform annular flow with respect to high gas velocity in the pipe. Also, the film thickness is nonuniform and flows across the pipe walls. Again, depending on the gas and liquid mass flow rate, the liquid film is characterized by asymmetry distributions, Setyawan et al., [6]. The impact of gravity-induced drainage, increases the annular flow liquid film at the bottom of the horizontal pipes, Setyawan et al., [6], Shedd, [7].

In the investigations of annular flow behaviors in horizontal pipe, the following were used conductivity ring sensors, conductance probes and high speed digital camera as shown in figure 1. For liquid film thickness, there are several experimental methods such as optical (high speed camera/laser for interface, pin etc.), electrical (capacitance, conductance, etc.), acoustic (ultrasonic) and radiological (X-ray, neutrons, gamma ray, etc.) but the optical and electrical methods were used for liquid film thickness experimentally.

Importantly, the experimental investigations in this study were conducted to progress the fundamental understanding of annular flow behaviors in pipes.

\section{Methods and Materials}

The investigation methods were basically experiments. The experiments were carried out using a 2 -inch $(0.0504$ m) flow loop of $28.68 \mathrm{~m}$ long. A 2-inch air injection pipe was connected to the flow loop immediately after the bend at $15.81 \mathrm{~m}$. More so, calibration of annular flow tests were conducted with the aid of five different acryl rods (blocks) of $49 \mathrm{~mm}, 48 \mathrm{~mm}, 47 \mathrm{~mm}, 46 \mathrm{~mm}$ and $45 \mathrm{~mm}$ with the calibrated resulted programed into the LabVIEW.

\subsection{Experimental Set-up}

In the experiments, a 2-inch closed pipeline flow loop with a total of length of $28.68 \mathrm{~m}$ from the water tank. The following apparatus were used; High speed Olympus camera, two pairs of Druck-PMP 4070 pressure transducers (P1, P2), installed at $2.13 \mathrm{~m}$ apart, temperature sensors, IR LED sensors, conductivity ring sensors of double pairs installed at $1.3 \mathrm{~m}$ apart as shown in figure 1. A 2-inch air-flow line with a vortex flowmeter was used to deliver air from a compressor with a total capacity of $30 \mathrm{~m} / \mathrm{s}$. These instruments were programmed into a Digital Data Acquisition System (DAQ) called LabVIEW.

The above Fig 1, is the 2-inch horizontal pipeline test loop connected to a water tank to function. The plastic fiber water storage tank which is in a cubic shape is used as a source of water supply to the 2-inch $(0.0504 \mathrm{~m})$ horizontal test pipeline. It has a capacity of $4.4 \mathrm{~m}^{3}$. The water tank is connected to the loop through a progressive cavity pump (PCP) of $90 \mathrm{~m}^{3} / \mathrm{h}$ capacity with maximum discharge pressure of $5 \mathrm{bar}$. The entire supply system to the 2-inch pipeline test lop is in a closed loop. The water storage tank is internally designed into two;

-The returning chamber; where water that was initially pumped into the test facility returns to.

-Suction chamber; this is by the side of the chamber that retains the returned water. The suction chamber acts as the source of the water. It supplies the water to the 2-inch pipeline test facility. The air used in this experiment was supplied by a compressor in the PSE laboratory. The compressor has capacity of $400 \mathrm{~m}^{3} / \mathrm{h}$ with a discharge pressure of 10barg. The gas was metered with a Vortex gas flow meter with a full range of $\left[0-70 \mathrm{~m}^{3} / \mathrm{h}\right]$ and manufacturer uncertainty of $\pm 1 \%$. The compressor could supply gas (air) through a 2 -inch $(0.0504 \mathrm{~m})$ air pipeline to the flow loop at a maximum superficial gas velocity of $30 \mathrm{~m} / \mathrm{s}$. From Figure 1 is a sketch of 2-inch $(0.0504 \mathrm{~m})$ pipeline flow loop 
with the colored lines as: The Red Line: gas supply, the Blue Line: water supply, the Pink Line: for multiphase flow, the Green Line: for sand/water mixture (slurry flow) from sand hopper though not part of this experiment. In the experiments, the under listed instruments in Table 1 with the following uncertainties and ranges were used.

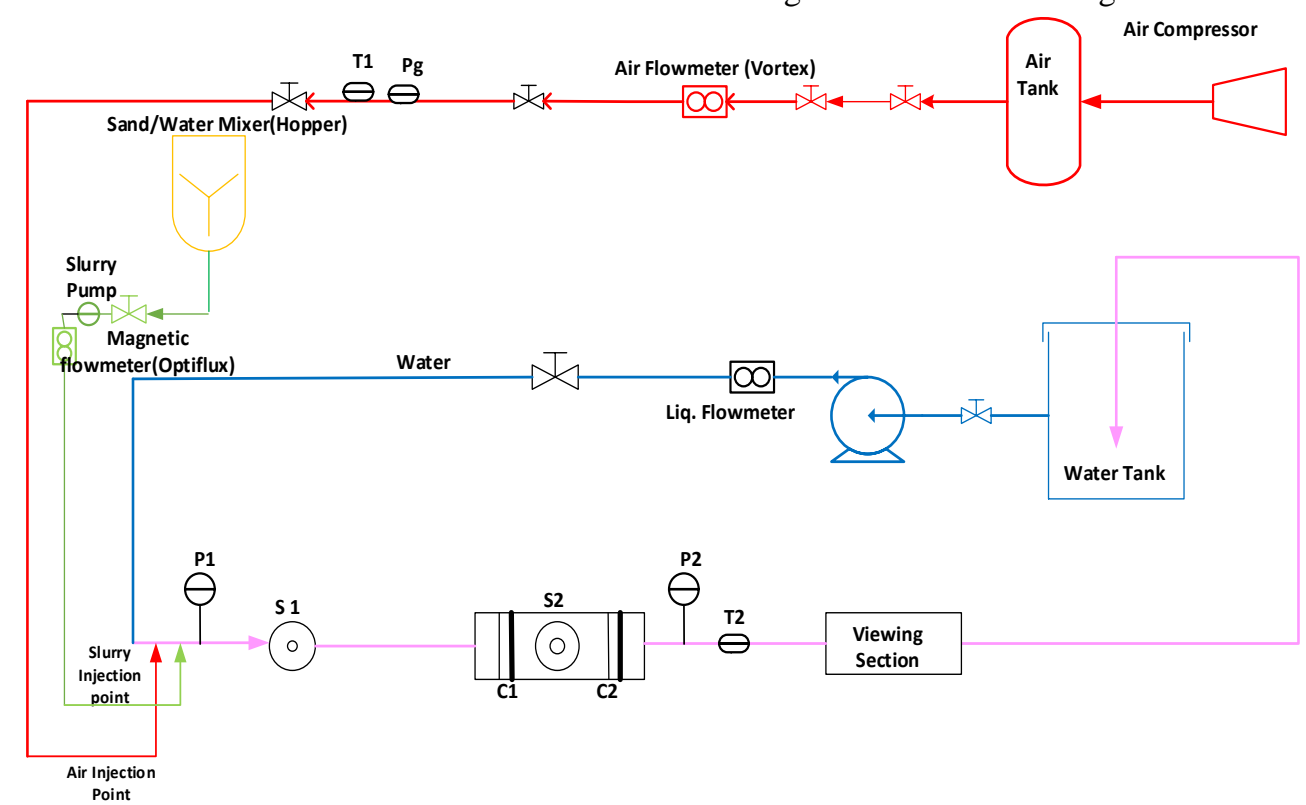

Fig. 1 - A sketch of 2-inch pipeline flow loop used

Table 1 - Instruments used showing their functions, uncertainty and full range

\begin{tabular}{ccc}
\hline Instruments & Functions & Uncertainty - [Full Range $]$ \\
\hline Gas Flowmeter Vortex & Air/gas Flow Metering & $\pm 1 \%\left[0 \sim 70 \mathrm{~m}^{3} / \mathrm{h}\right]$ \\
\hline Liquid flowmeter & Liquid Flow Metering & $\pm 0.8 \%\left[0 \sim 20 \mathrm{~m}^{3} / \mathrm{h}\right]$ \\
\hline Pump & Water/sand pump & {$[0-300 \mathrm{~L} / \mathrm{h}]$} \\
\hline Pressure Transducer [P1] & Pressure Measurement & $\pm 0.04 \%[0-6 \mathrm{bara}, 0-100 \mathrm{psi}]$ \\
\hline Pressure Transducer [P2] & Pressure Measurement & $\pm 0.06 \%[0-6 \mathrm{bara}, 0-100 \mathrm{psi}]$ \\
\hline Conductivity Probe Sensor [S1] & Film thickness, Sand detector & $\pm 3.6 \%[0-3.8 \mathrm{~mm}]$ \\
\hline Conductivity Probe Sensor [S2] & Film thickness, Sand detector & $\pm 3.6 \%[0-3.8 \mathrm{~mm}]$ \\
\hline Conductivity Ring Sensor [C1] & Liquid hold-up & $\pm 2.3 \%[0-1]$ \\
\hline Conductivity Ring Sensor [C2] & Liquid Hold-up & $\pm 2.3 \%[0-1]$ \\
\hline Thermocouple [Temperature Sensors T1-T2] & Temperature Measurement & $\pm 0.5 \%\left[0^{\circ}-100^{\circ} \mathrm{c}\right]$ \\
\hline
\end{tabular}

Table 2 - Experimental properties, range and used

\begin{tabular}{lcc}
\multicolumn{1}{c}{ Properties } & Ranges & Unit \\
\hline Temperature (T) & $16.5-19.3$ & ${ }^{0} \mathrm{C}$ \\
\hline Pipe (D) & 0.0504 & $\mathrm{~m}$ \\
\hline Air flow line & 0.0504 & $\mathrm{~m}$ \\
\hline Superficial Liquid Velocity (Vsl) & $0.0501-0.2001$ & $\mathrm{~m} / \mathrm{s}$ \\
\hline Superficial Gas Velocity (Vsg) & $8.0774-23.7260$ & $\mathrm{~m} / \mathrm{s}$
\end{tabular}

\subsection{Annular Flow Calibrations using Sensors}

A 2-inch $(50 \mathrm{~mm})$ Plexiglas horizontal pipe test tube with a length of $154 \mathrm{~mm}$ was used for annular flow bench calibration. The experimental pipe test tube set-up had two pairs of conductivity ring sensors of upstream and downstream as $\mathrm{C} 1$ and $\mathrm{C} 2$ respectively, installed at $70 \mathrm{~mm}$ apart on the external surface of outer diameter of the pipe. 
Installed also, was a conductance probe sensor which is illustrated in figure 3 below. The conductivity ring sensor and the conductance probe sensor were connected directly with black coated flexible wires to the receiver as shown in figure 2 . The receiver conveys the signals to the central processing unit were the signals were recorded in a Labview as the calibrations were being conducted.

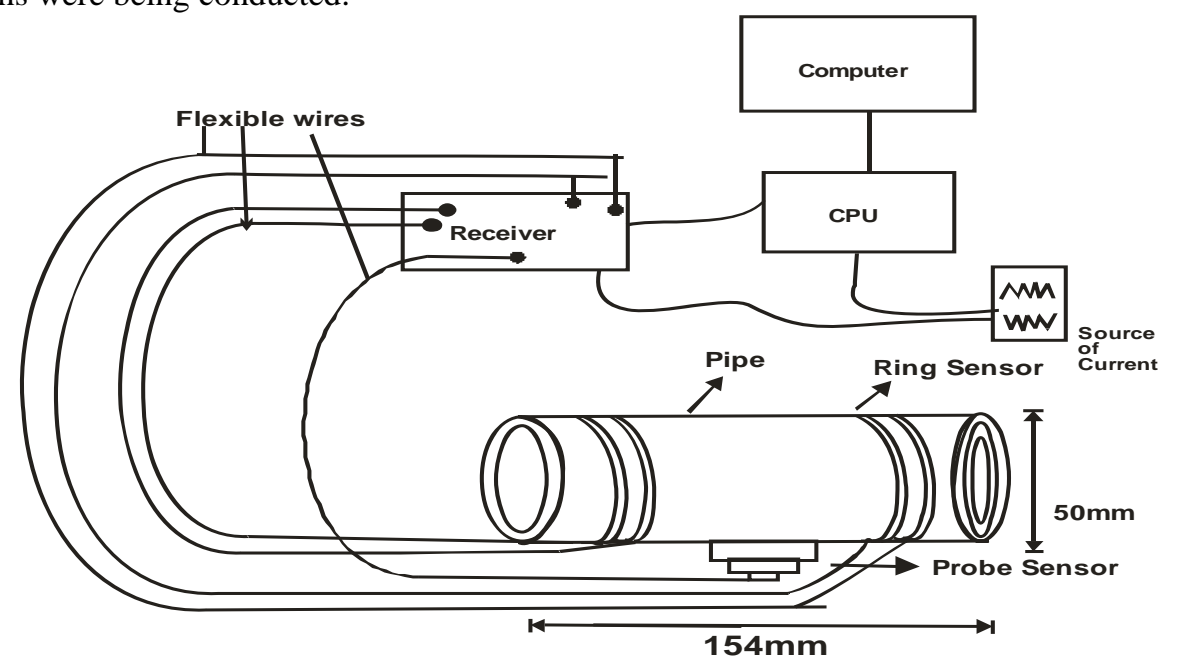

Fig. 2 - A sketch of the experimental 2-inch calibration tool and its connections

\subsubsection{Conductance Probe Sensors}

Conductance probe sensors were used to detect liquid film thickness or liquid phase based on the conductivity reaction relative to water. The sensors have two electrodes, a central circular plate electrode of $10.25 \mathrm{~mm}$ in diameter (inner conductor) and the outer circular plate of $1.80 \mathrm{~mm}$ (outer conductor). The circular insulator of $2.40 \mathrm{~mm}$ is separated by two circular plates as presented in Figure 3. The probe sensors which is labelled in the sketch of figure 2 was flush-mounted internally in the pipe diameter.
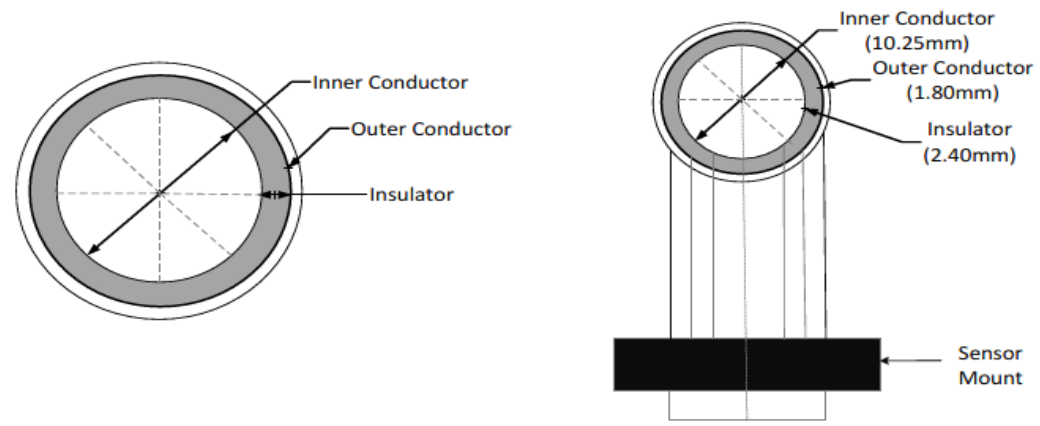

Fig. 3 - A Sketch of conductance probe sensors used

In figure 4 is the horizontal Plexiglas test tube which was sealed at both ends with liquid drain holes of $6 \mathrm{~mm}$. The end cap (seals) were drilled at the center with a diameter of $25.02 \mathrm{~mm}$ to a depth of $10 \mathrm{~mm}$. The essence was to enable the acryl rods to be fixed firmly at the center position of the $50 \mathrm{~mm}$ test tube as part of the precautions for having a circumferential liquid film thickness across the pipe internal diameter. The drains were used for water passage: draining and introducing fresh water during the calibrations with a stopper. Also, in figure 4 is one of the samples of the acryl rods (blocks) used to replicate annular flow conditions in pipes. However, these acryl rods (blocks) as shown in figure 5 with sizes indicated were used in the calibration. The calibrated results were therefore programed into the digital date recorded (DEQ) LabVIEW in order to validate the experimental runs that were conducted. 


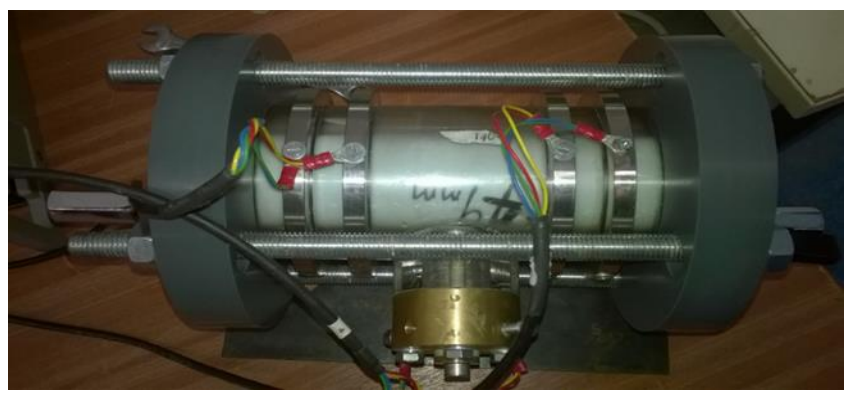

Fig. 4 - Bench annular flow calibration with both rings and probe sensors

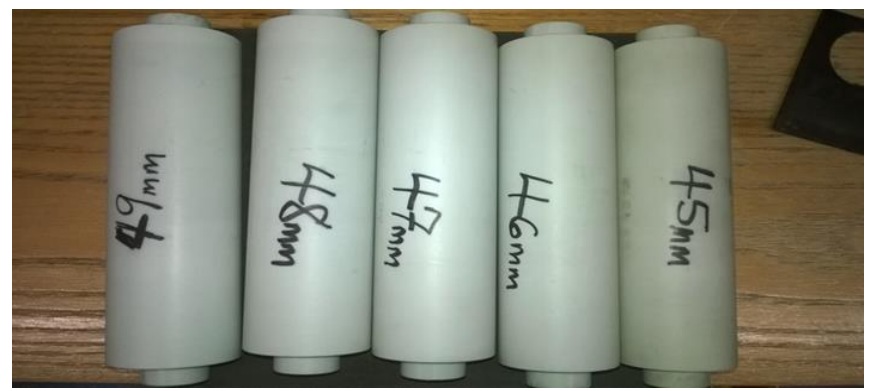

Fig. 5 - The five acryl rods (blocks) used for annular flow calibration

\subsection{Data Analysis}

The experimental signals of the annular flow in pipes from conductivity ring sensors were further analyzed using: probability density function (PDF), power spectral density, (PSD) and wavelet to present wave characteristics in pipes:

Probability Density Function on Film Thickness: This is a probability time series function that describes the statistical distribution of the instantaneous film thickness. It is a statistical function that gives a random variable on a range of values. Mathematically, PDF could be expressed using equation 1:

$$
f X(x)=\frac{\operatorname{Lim}}{\Delta \rightarrow 0^{+}} \frac{P\{x<X \leq x+\Delta\}}{\Delta}
$$

Power Spectral Density on Film Thickness: Power spectral density is an autocorrelation signal analysis functions, which measures the power intensity signals with respect to frequency domain. It illustrates how energy strength of the output signals on time series, are distributed with respect to frequency of that signal. The power spectral density is used to determine wave frequency in multiphase flow in pipes using Matlab.

Wavelet on Film Thickness: The continuous wavelet transform (CWT), is a short time Fourier transform that is used to analysis signals at multiple scales. In extracting output signals from experimental data, the continuous wavelet transform (CWT) uses an analysis window which is referred to as wavelet. Wavelet is a signal analysis that exhibits time-varying statistics in both time scales, and in frequency domain with a plot of output signals and the scale wavelet called scalogram, Shoeb and Clifford, [8]. Continuous wavelet transform could be expressed using equation 2 and this is basis of the program which is used in Matlab to determine the wavelet analysis based on the code generated.

$$
C_{(a, \tau)}=\int \frac{1}{\sqrt{a}} \Psi\left(\frac{t-\tau}{a}\right) x(t) d t
$$

\section{Results and Discussions}

From the experiments conducted using conductivity ring sensors, the superficial liquid velocities were plotted against the superficial gas velocities on a log-log flow regime map of Taitel and Dukler [9] for horizontal pipes as shown in figure 6. Annular flow conditions were obtained with superficial liquid and gas velocities between 0.0501 $\mathrm{m} / \mathrm{s}-0.1950 \mathrm{~m} / \mathrm{s}$ and $8.0774 \mathrm{~m} / \mathrm{s}-23.7260 \mathrm{~m} / \mathrm{s}$ respectively. As shown in figure 6 , the transitions from stratified-wavy to annular flow were observed in average superficial liquid velocities of $0.0505 \mathrm{~m} / \mathrm{s}$ and $0.0714 \mathrm{~m} / \mathrm{s}$ from average superficial gas velocities of $8.2699 \mathrm{~m} / \mathrm{s}$ to $12.0675 \mathrm{~m} / \mathrm{s}$. The transitions that were detected from the conductivity ring sensors were in line with the observations referred in annular-wavy flow in table 3 . While at average superficial liquid 
velocities of $0.0903 \mathrm{~m} / \mathrm{s}, 0.1355 \mathrm{~m} / \mathrm{s}$ and $0.1851 \mathrm{~m} / \mathrm{s}$ annular flow regimes were obtained from superficial gas velocities of $8.2699 \mathrm{~m} / \mathrm{s}$ to $23.7260 \mathrm{~m} / \mathrm{s}$. From the experiments, we discovered that annular flow in horizontal pipe travels with liquid film at the bottom of the pipe at the superficial gas and liquid velocities. This is simple because of gravity and shear stress as noted by Sergey et al., [2]. Again, we discovered at the upper walls of the pipe where the liquid film is thin, that the liquid film traves as wavy flow as seen in figures 7 and 8 below. This illustrates that at all annular flow conditions, the liquid film at the upper walls of the pipe, behavior as wavy-flow. The difference between the wavy-flow at Vsl $=0.0501 \mathrm{~m} / \mathrm{s}$ and $\mathrm{Vsg} 23.2796 \mathrm{~m} / \mathrm{s}$ and that of $\mathrm{Vsl}=0.0901 \mathrm{~m} / \mathrm{s}, \mathrm{Vsg}=23.5707 \mathrm{~m} / \mathrm{s}$ is the speed at which the wavy moves. At higher gas velocity and higher liquid velocity, the wavy moves faster and spreads across as seen in figure 8.

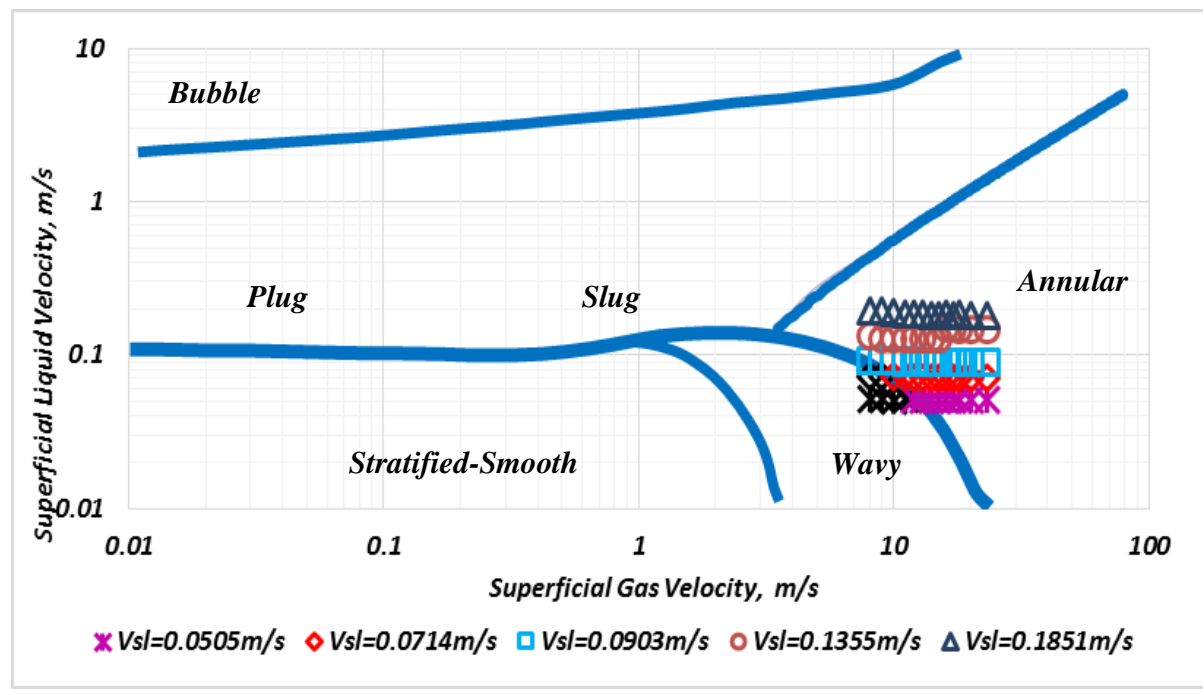

Fig. 6 - Experimental Annular Flow Regime matched with Taitel \& Dukkler [9]
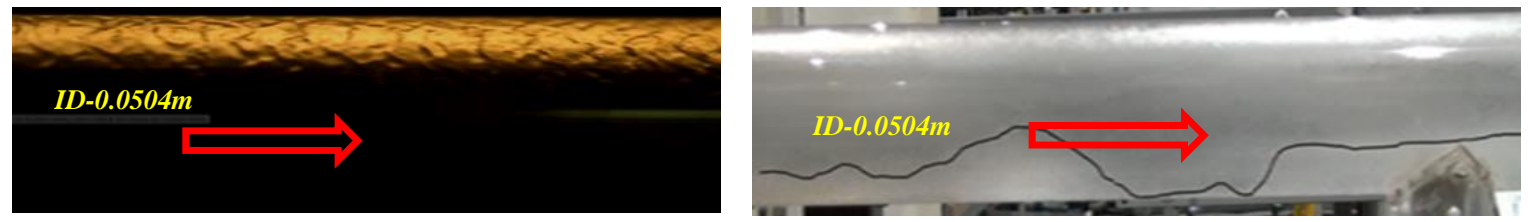

Fig. 7 - Wavy-flow of the upper pipe walls of Annular at Vsl=0.0501 m/s, Vsg =23.2796 m/s
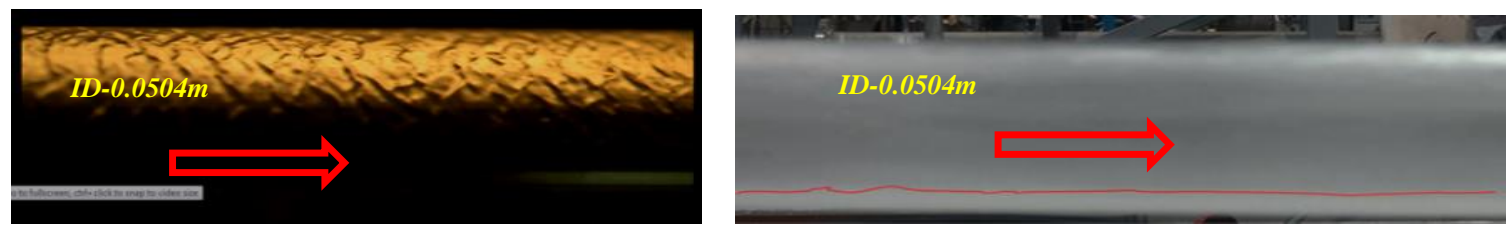

Fig. 8 - Wavy-flow of the upper pipe walls of Annular at Vsl=0.0901 m/s, Vsg=23.5707 m/s

In Table 3, at Vsg $=8.2699 \mathrm{~m} / \mathrm{s}-12.0675 \mathrm{~m} / \mathrm{s}$ with respect to $\mathrm{Vsl}$ of $0.0505 \mathrm{~m} / \mathrm{s}-0.1355 \mathrm{~m} / \mathrm{s}$, we discovered that annular flow behaves as annular-slug flow in pipe. This is because as liquid velocity increases, the high gas velocity pushes the liquid more which results to slug at those stages. From Table 3, A means Annular flow fully, A+S $=$ Annular-wavy with slug flow, $\mathrm{A}+\mathrm{Sr}=$ Annular-slug but slug reduces, $\mathrm{L}-\mathrm{T}=$ More liquid film at the bottom of the pipe, $\mathrm{L}-\mathrm{Ts}=$ More liquid film thickness at the bottom but moves with more speed, $\mathrm{w}-\mathrm{d}=$ Wavy flow at upper walls of the pipe and drain down through the pipe walls to the bottom of the pipe, $w$-ds = Wavy flow at the upper pipe walls and drain down the pipe walls to the bottom of the pipe at higher speed, $w-f=$ Wavy flow at upper walls of the pipe with speed, wl-c $=$ the pipe walls are fully covered with liquid film at high speed, $\mathrm{w}-\mathrm{cr}=$ the pipe walls are fully covered with liquid film at very high speed at the entire walls of the pipe.

More so, the analysis on Table 3 were analyzed results obtained using conductivity sensors in the experiments. The annular flow behaviors were also carefully observed and recorded using an Olympia high speed digital camera in the cause of the experiments to serve as a reconfirmation/validation. 


\subsection{Void fraction and Probability Density Function in Annular Flow}

The void fraction against time on Table 4 illustrates that lower superficial liquid velocity promotes shorter wave circle in the pipe as shown in Vsl=0.0508 m/s and Vsg=10.0773 m/s and likewise $0.0501 \mathrm{~m} / \mathrm{s}$ and $\mathrm{Vsg}=23.2796 \mathrm{~m} / \mathrm{s}$. While higher superficial liquid velocity (Vsl), creates longer wave circle in horizontal pipes as shown on Vsl=0.1892 $\mathrm{m} / \mathrm{s}$ and $\mathrm{Vsg}=10.3927 \mathrm{~m} / \mathrm{s}$ as well as Vsl $=0.1805 \mathrm{~m} / \mathrm{s}$ and Vsg=23.7259 m/s. Probability time series function describes the statistical distribution of the instantaneous film thickness. For Vsl $=0.0508 \mathrm{~m} / \mathrm{s}$ with $\mathrm{Vsg}=10.0773 \mathrm{~m} / \mathrm{s}$ and 0.0501 $\mathrm{m} / \mathrm{s}$ with respect to $\mathrm{Vsg}=23.2796 \mathrm{~m} / \mathrm{s}$, it has shown that the lower the superficial liquid velocities, the higher the void fraction and more thin the film thickness in the pipe. As superficial liquid velocity increases, the void fraction reduces with increase in film thickness.

Table 3 - Annular Flow matrixes showing the flow behavior in 2-inch horizontal pipe

\begin{tabular}{|c|c|c|c|c|c|c|c|c|c|c|c|c|c|}
\hline $\begin{array}{c}\text { Vsg } \\
(\mathrm{m} / \mathrm{s})\end{array}$ & 8.2699 & 9.2654 & 10.2160 & 11.2251 & 12.0675 & 13.1692 & 14.2883 & 15.3236 & 16.2262 & 17.3086 & 18.2481 & 20.3842 & 23.4575 \\
\hline $\begin{array}{c}0.0505 \\
\text { Vsl } \\
(\mathrm{m} / \mathrm{s})\end{array}$ & $\begin{array}{c}\mathrm{A}+\mathrm{S} \\
\mathrm{L}-\mathrm{T}\end{array}$ & $\begin{array}{l}A+S \\
L-T \\
w-d\end{array}$ & $\begin{array}{l}A+S \\
L-T \\
w-f\end{array}$ & $\begin{array}{c}\mathrm{A}+\mathrm{S} \\
\mathrm{L}-\mathrm{Ts} \\
\mathrm{w}-\mathrm{f}\end{array}$ & $\begin{array}{c}\mathrm{A}+\mathrm{S} \\
\mathrm{L}-\mathrm{Ts} \\
\mathrm{w}-\mathrm{f}\end{array}$ & $\begin{array}{c}\text { A } \\
\text { L-Ts } \\
\text { w-f }\end{array}$ & $\begin{array}{c}\text { A } \\
\text { L-Ts } \\
\text { w-f } \\
\text { wl-c }\end{array}$ & $\begin{array}{c}\text { A } \\
\text { L-Ts } \\
\text { w-f } \\
\text { wl-c }\end{array}$ & $\begin{array}{c}\text { A } \\
\text { L-Ts } \\
\text { w-f } \\
\text { wl-c }\end{array}$ & $\begin{array}{c}\text { A } \\
\text { L-Ts } \\
\text { w-f } \\
\text { wl-c }\end{array}$ & $\begin{array}{c}\text { A } \\
\text { L-Ts } \\
\text { w-f } \\
\text { wl-c }\end{array}$ & $\begin{array}{c}\text { A } \\
\text { L-Ts } \\
\text { W-f } \\
\text { w-cr }\end{array}$ & $\begin{array}{c}\text { A } \\
\text { L-Ts } \\
\text { w-f } \\
\text { w-cr }\end{array}$ \\
\hline $\begin{array}{c}0.0714 \\
\text { Vsl } \\
(\mathrm{m} / \mathrm{s})\end{array}$ & $\begin{array}{l}\text { A+S } \\
\text { L-T } \\
w-d\end{array}$ & $\begin{array}{l}\mathrm{A}+\mathrm{S} \\
\mathrm{L}-\mathrm{T} \\
\mathrm{w}-\mathrm{d}\end{array}$ & $\begin{array}{l}\mathrm{A}+\mathrm{S} \\
\mathrm{L}-\mathrm{T} \\
\mathrm{w}-\mathrm{f}\end{array}$ & $\begin{array}{c}\mathrm{A}+\mathrm{Sr} \\
\mathrm{L}-\mathrm{T} \\
\mathrm{w}-\mathrm{f}\end{array}$ & $\begin{array}{c}\text { A+Sr } \\
\text { L-Ts } \\
\text { w-f } \\
\text { wl-c }\end{array}$ & $\begin{array}{c}\mathrm{A}+\mathrm{Sr} \\
\mathrm{L}-\mathrm{Ts} \\
\mathrm{w}-\mathrm{f} \\
\text { wl-c }\end{array}$ & $\begin{array}{c}\text { A } \\
\text { L-Ts } \\
\text { W-f } \\
\text { wl-c }\end{array}$ & $\begin{array}{c}\text { A } \\
\text { L-Ts } \\
\text { w-f } \\
\text { wl-c }\end{array}$ & $\begin{array}{c}\text { A } \\
\text { L-Ts } \\
\text { w-f } \\
\text { wl-c }\end{array}$ & $\begin{array}{c}\text { A } \\
\text { L-Ts } \\
\text { w-f } \\
\text { wl-c }\end{array}$ & $\begin{array}{c}\text { A } \\
\text { L-Ts } \\
\text { w-f } \\
\text { w-cr }\end{array}$ & $\begin{array}{c}\text { A } \\
\text { L-Ts } \\
\text { w-f } \\
\text { w-cr }\end{array}$ & $\begin{array}{c}\text { A } \\
\text { L-Ts } \\
\text { w-f } \\
\text { w-cr }\end{array}$ \\
\hline $\begin{array}{c}0.0903 \\
\text { Vsl } \\
(\mathrm{m} / \mathrm{s})\end{array}$ & $\begin{array}{l}\text { A+S } \\
\text { L-T } \\
\text { w-d }\end{array}$ & $\begin{array}{c}\mathrm{A}+\mathrm{Sr} \\
\mathrm{L}-\mathrm{T} \\
\mathrm{w}-\mathrm{d}\end{array}$ & $\begin{array}{c}\mathrm{A}+\mathrm{Sr} \\
\mathrm{L}-\mathrm{T} \\
\mathrm{w}-\mathrm{d}\end{array}$ & $\begin{array}{c}\mathrm{A}+\mathrm{Sr} \\
\mathrm{L}-\mathrm{T} \\
\mathrm{w}-\mathrm{d}\end{array}$ & $\begin{array}{c}\text { A+Sr } \\
\text { L-T } \\
\text { w-f }\end{array}$ & $\begin{array}{c}\text { A } \\
\text { L-Ts } \\
\text { w-f } \\
\text { wl-c }\end{array}$ & $\begin{array}{c}\text { A } \\
\text { L-Ts } \\
\text { W-f } \\
\text { wl-c }\end{array}$ & $\begin{array}{c}\text { A } \\
\text { L-Ts } \\
\text { w-f } \\
\text { wl-c }\end{array}$ & $\begin{array}{c}\text { A } \\
\text { L-Ts } \\
\text { w-f } \\
\text { wl-c }\end{array}$ & $\begin{array}{c}\text { A } \\
\text { L-Ts } \\
\text { w-f } \\
\text { wl-c }\end{array}$ & $\begin{array}{c}\text { A } \\
\text { L-Ts } \\
\text { w-f } \\
\text { w-cr }\end{array}$ & $\begin{array}{c}\text { A } \\
\text { L-Ts } \\
\text { w-f } \\
\text { w-cr }\end{array}$ & $\begin{array}{c}\text { A } \\
\text { L-Ts } \\
\text { w-f } \\
\text { w-cr }\end{array}$ \\
\hline $\begin{array}{c}0.1355 \\
\text { Vsl } \\
(\mathrm{m} / \mathrm{s})\end{array}$ & $\begin{array}{c}\text { A } \\
\text { L-T } \\
\text { w-d }\end{array}$ & $\begin{array}{c}\text { A } \\
\text { L-T } \\
\text { w-ds }\end{array}$ & $\begin{array}{c}\text { A } \\
\text { L-T } \\
\text { w-ds }\end{array}$ & $\begin{array}{c}\text { A } \\
\text { L-T } \\
w-f\end{array}$ & $\begin{array}{c}\text { A } \\
\text { L-T } \\
\text { w-f }\end{array}$ & $\begin{array}{c}\text { A } \\
\text { L-Ts } \\
\text { w-f } \\
\text { wl-c }\end{array}$ & $\begin{array}{c}\text { A } \\
\text { L-Ts } \\
\text { W-f } \\
\text { wl-c }\end{array}$ & $\begin{array}{c}\text { A } \\
\text { L-Ts } \\
\text { w-f } \\
\text { wl-c }\end{array}$ & $\begin{array}{c}\text { A } \\
\text { L-Ts } \\
\text { w-f } \\
\text { wl-c }\end{array}$ & $\begin{array}{c}\text { A } \\
\text { L-Ts } \\
\text { w-f } \\
\text { w-cr }\end{array}$ & $\begin{array}{c}\text { A } \\
\text { L-Ts } \\
\text { w-f } \\
\text { w-cr }\end{array}$ & $\begin{array}{c}\text { A } \\
\text { L-Ts } \\
\text { w-f } \\
\text { w-cr }\end{array}$ & $\begin{array}{c}\text { A } \\
\text { L-Ts } \\
\text { w-f } \\
\text { w-cr }\end{array}$ \\
\hline $\begin{array}{c}0.1851 \\
\text { Vsl } \\
(\mathrm{m} / \mathrm{s})\end{array}$ & $\begin{array}{c}\text { A } \\
\text { L-T } \\
\text { w-d }\end{array}$ & $\begin{array}{c}\text { A } \\
\text { L-T } \\
\text { w-d }\end{array}$ & $\begin{array}{c}\text { A } \\
\text { L-T } \\
\text { w-d }\end{array}$ & $\begin{array}{c}\text { A } \\
\text { L-T } \\
\text { w-f }\end{array}$ & $\begin{array}{c}\text { A } \\
\text { L-T } \\
w-f\end{array}$ & $\begin{array}{c}\text { A } \\
\text { L-T } \\
\text { w-f }\end{array}$ & $\begin{array}{c}\text { A } \\
\text { L-Ts } \\
\text { w-f } \\
\text { wl-c }\end{array}$ & $\begin{array}{c}\text { A } \\
\text { L-Ts } \\
\text { w-f } \\
\text { wl-c }\end{array}$ & $\begin{array}{c}\text { A } \\
\text { L-Ts } \\
\text { w-f } \\
\text { wl-c }\end{array}$ & $\begin{array}{c}\text { A } \\
\text { L-Ts } \\
\text { w-f } \\
\text { w-cr }\end{array}$ & $\begin{array}{c}\text { A } \\
\text { L-Ts } \\
\text { w-f } \\
\text { w-cr }\end{array}$ & $\begin{array}{c}\text { A } \\
\text { L-Ts } \\
\text { w-f } \\
\text { w-cr }\end{array}$ & $\begin{array}{c}\text { A } \\
\text { L-Ts } \\
\text { w-f } \\
\text { w-cr }\end{array}$ \\
\hline
\end{tabular}

\subsection{Power Spectral Density (PSD) Analysis on Film Thickness}

The PSD which measures the power intensity signal, frequency domain and energy strength was used to establish the wave frequency from the conductivity ring sensors' data using Mtalab. The dominant frequency is more prominent with disturbance waves which covers the pipe circumference as noted by Paras and Karabelas [10]. In Figure 9 (a) with Vsl $=0.0508 \mathrm{~m} / \mathrm{s}$ and $\mathrm{Vsg}=10.0773 \mathrm{~m} / \mathrm{s}$, shows a high energy strength with much frequency while in Figure 9 (b), the $\mathrm{Vsl}=0.0501 \mathrm{~m} / \mathrm{s}$ and $\mathrm{Vsg}=23.2796 \mathrm{~m} / \mathrm{s}$ shows a low energy strength. Again, the impact of the high superficial gas velocity with low superficial liquid velocity, created a very thin film thereby leaving less energy and less frequency. Ordinarily, the higher the superficial liquid velocity, the higher the wave amplitude. This means the higher the wave amplitude, the more energy to keep the waves in motion.

\subsection{Wavelet Analysis on Film Thickness}

The essence of wavelet is to give more insight on film thickness signals in line with the information obtained already from the spectral density analysis graphs. Again, wavelet is less complex compare to PSD in analyzing any experimental data on signals. This was also noted by Jones and Zuber [11], Vince and Lahey [12]. Wavelet provides better understanding of time-resolved frequency information even with the aid of a scalogram, McClusky at el., [13].

Wavelet analysis comprises of various applications called wavelet family. They are Haar, Daubechies, Symlets, Coiflets, Biorthogonal, Reverse Biorthogonal, Meyer, Gaussian, Mexican, Morlet, Complex-Morlet (Gabor), Shannon, Fejer-Korovkin, etc. The choice from the family is based on accurate extraction of signals from your experimental data. In this research, the symlet application was used. The analysis in figures 9 and 10 were based on continuous wavelet transforms (CWT) of the film thickness signals in annular flow. The wavelet was used on the film thickness data to analyse; frequency-time variation and scalogram. The cwt of film thickness analysis of each signal from the experiment data covers (36011 data points) from a scan duration of 180s. The scalograms on figures 11 and 12 presents a space (frame) on the abscissa using (50 frame interval) as 1s with frequency on the ordinate from 1-31 while the coloration represents the wavelet energy density. 
Figure 9 with $\mathrm{Vsl}=0.0508 \mathrm{~m} / \mathrm{s}$ and $\mathrm{Vsg}=10.0773 \mathrm{~m} / \mathrm{s}$ and that of $0.0501 \mathrm{~m} / \mathrm{s}$ and $23.2796 \mathrm{~m} / \mathrm{s}$ illustrates the magnitude of wavelet signals at a given time and frequency. According to McClusky et al., [13], the dominant frequency reveals the passage of gas bubble in the flow. The wave signals were more on lower liquid velocity.

Table 4 - Time series and probability density function in annular flow

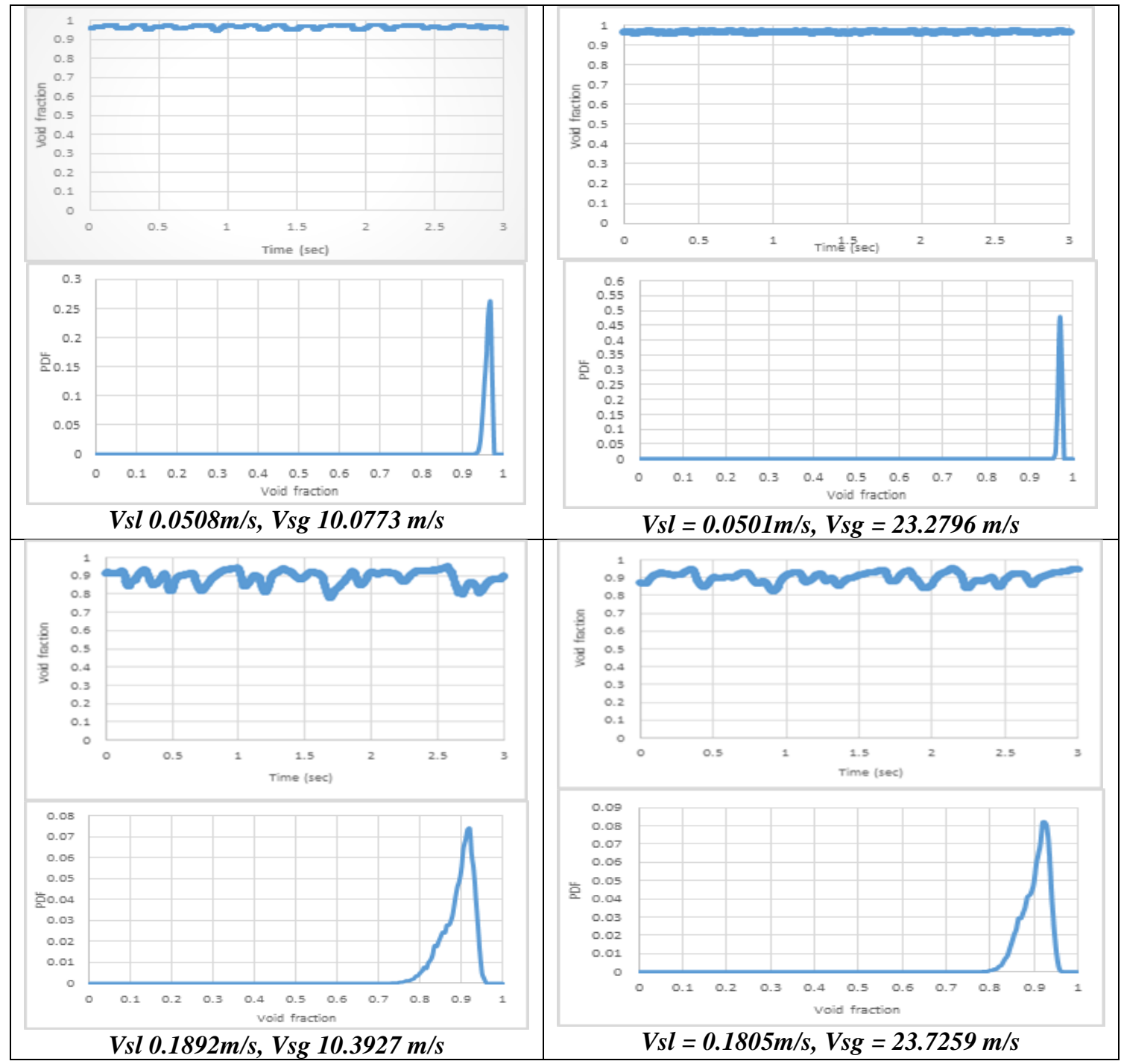

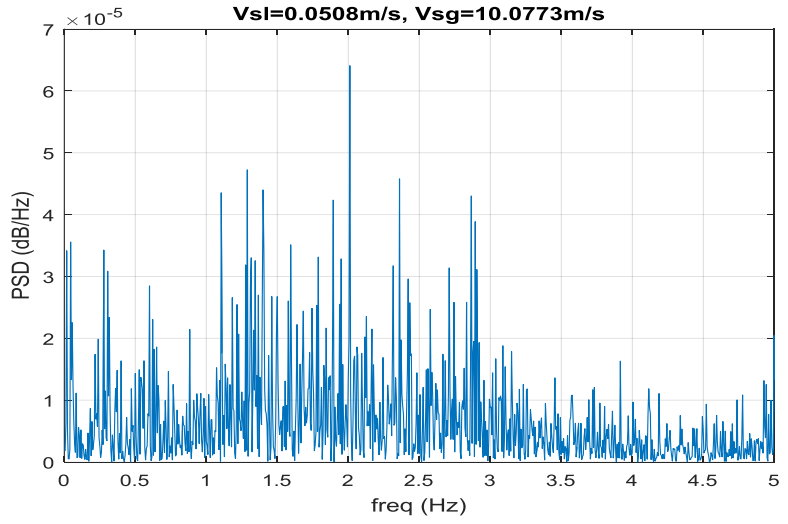

(a)

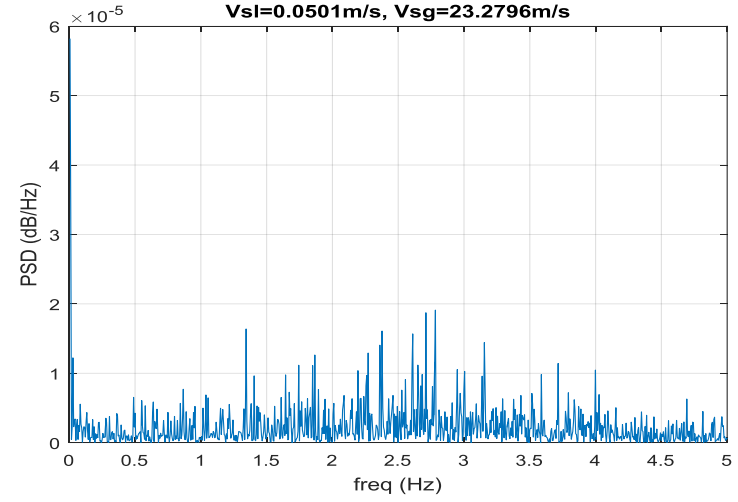

(b)

Fig. 9 - (a) \& (b) Power spectral density against frequency for low superficial liquid velocities 


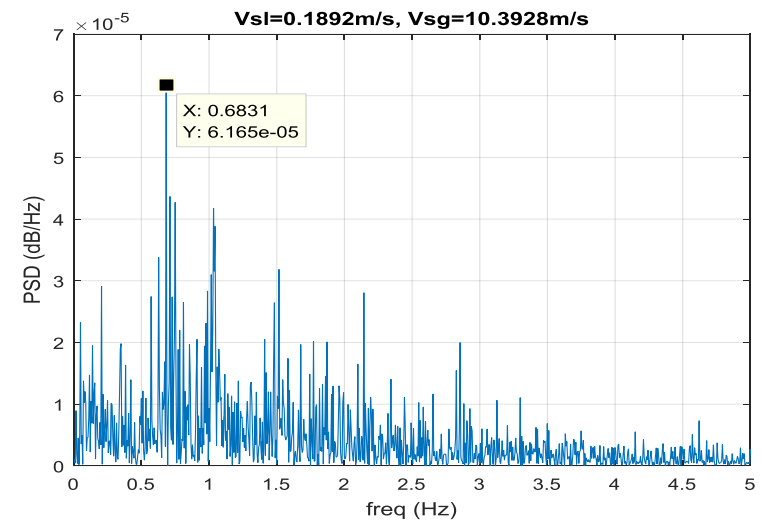

(a)

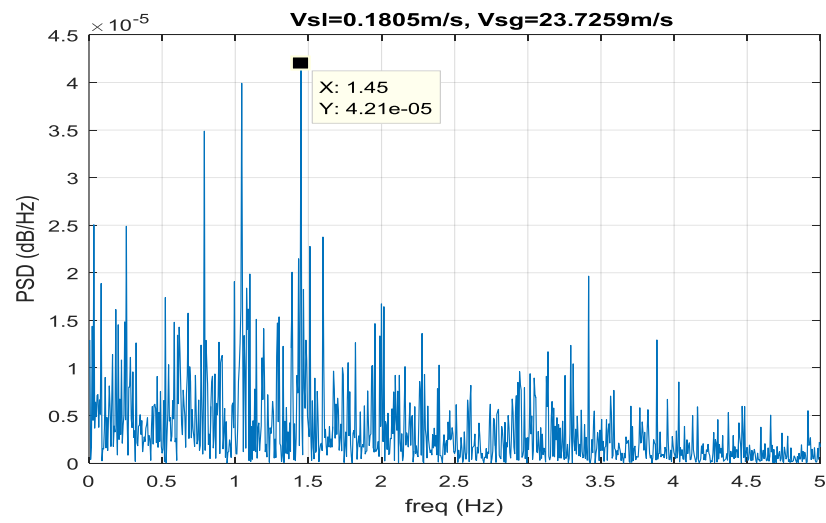

(b)

Fig. 10 - (a) \& (b) Power spectral density against frequency for high superficial liquid velocities.
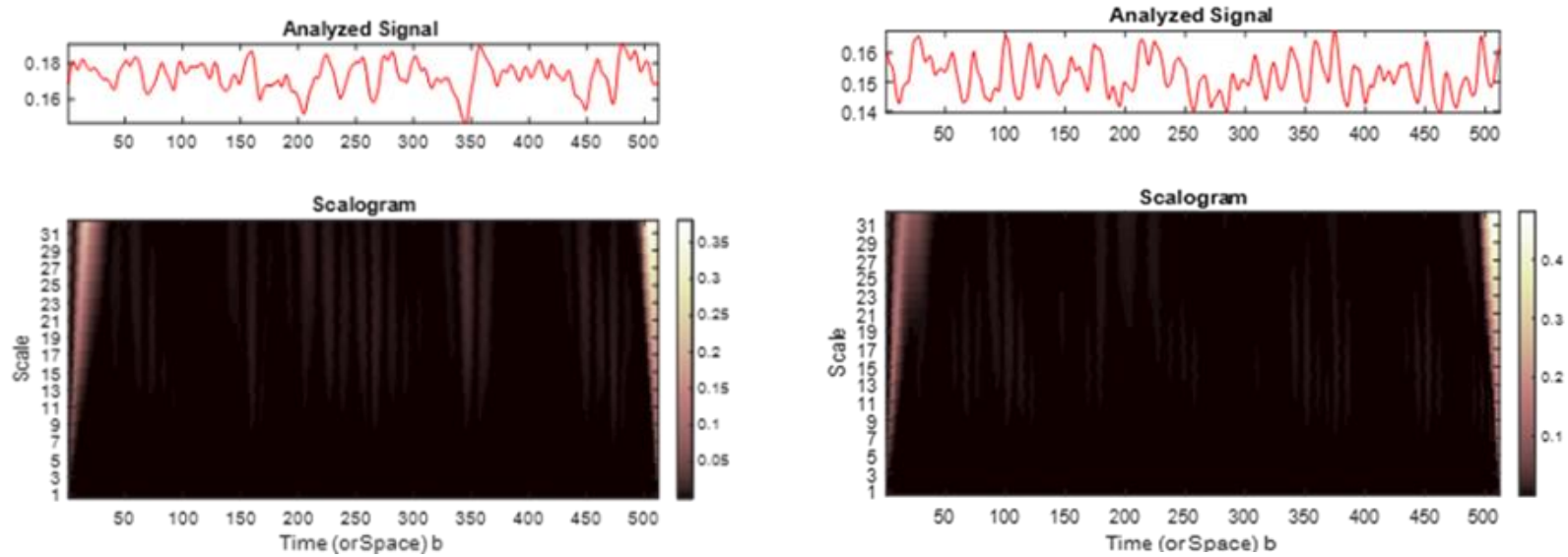

Fig. 11 - (a) Vsl=0.0508 m/s, Vsg=10.0773 m/s; (b) Vsl=0.0501 m/s, Vsg = $23.2796 \mathrm{~m} / \mathrm{s}$
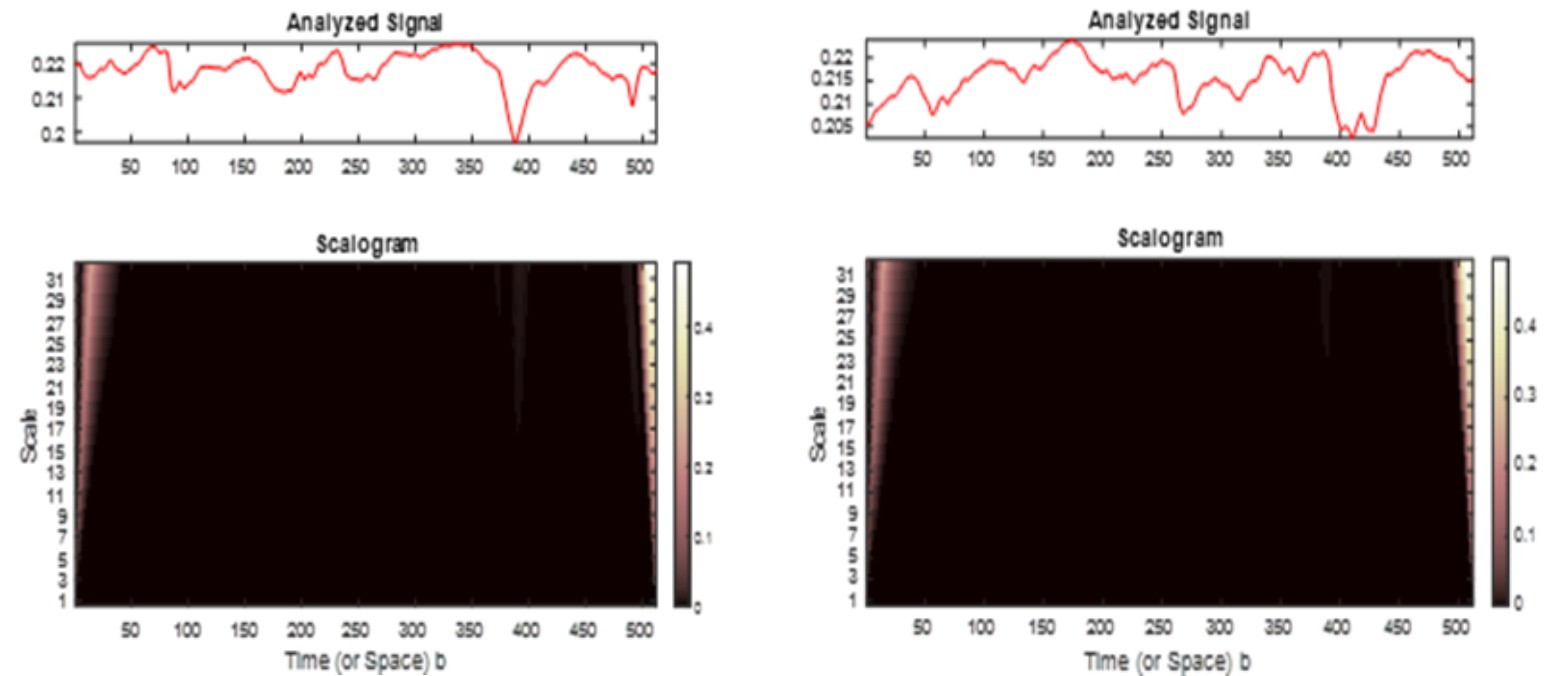

Fig. 12 - (a) Vsl=0.1892 m/s, Vsg=10.3927 m/s; (b) Vsl=0.1805 m/s, Vsg=23.7259 m/s

\subsection{Film Thickness}


The above figures 11 and 12 film thickness with time illustrates further that the wavy condition in annular flow in horizontal pipe reduces as the superficial liquid velocity increases. This was likewise reported by Paras and Karabelas [10]. Thus, the film thickness from Vsl $=0.0508 \mathrm{~m} / \mathrm{s}$ shows high wavy flow at the base (bottom) of the internal pipe compared to film thickness from $\mathrm{Vsl}=0.1892 \mathrm{~m} / \mathrm{s}$. This is because of low impact of inertial force, low velocity and surface tension influence on low superficial liquid velocity.

The graph of figure 11 represents a predominant disturbance wave effect at low superficial liquid velocity. The waves from figure 11 (a) \& (b), were dominant at a peak less than $0.1892 \mathrm{~mm}$ of film thickness. This is to ascertain that there were annular-wavy flows with much liquid film at the bottom of the pipe compared to figure 12 with superficial liquid velocity of $0.1892 \mathrm{~m} / \mathrm{s}$.
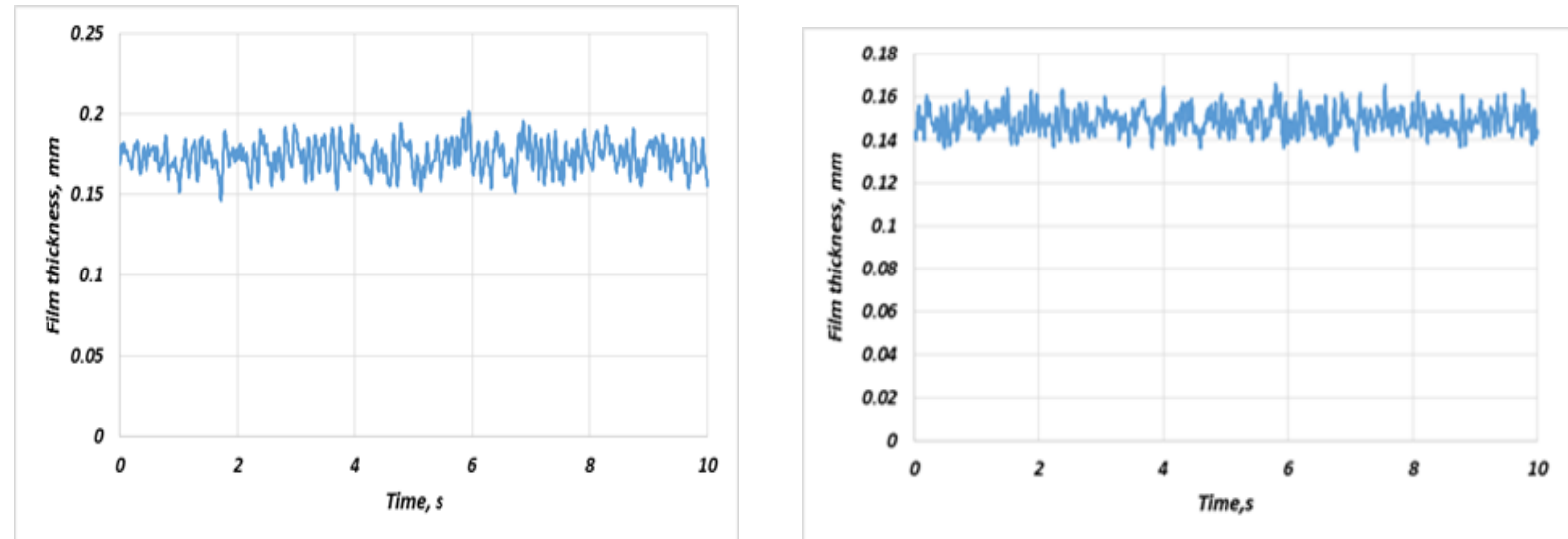

Fig. 13 - (a) Vsl = $0.0508 \mathrm{~m} / \mathrm{s}$, vsg =10.0773 m/s; (b) Vsl $=0.0501 \mathrm{~m} / \mathrm{s}, \mathrm{Vsg}=23.2796 \mathrm{~m} / \mathrm{s}$

Figure 14 (a) and (b) graphs of film thickness against high superficial liquid velocity were compared with figure 13. In figure 14 , average $\mathrm{Vsl}=0.1892 \mathrm{~m} / \mathrm{s}$ and $0.1805 \mathrm{~m} / \mathrm{s}$ with respect to average $\mathrm{Vsg}=10.3927 \mathrm{~m} / \mathrm{s}$ and 23.7259 $\mathrm{m} / \mathrm{s}$ shows that the disturbance wave have more longer spikes than those seen in figure 13 (a) and (b) with shorter and closer ripple waves that covered the entire distance.
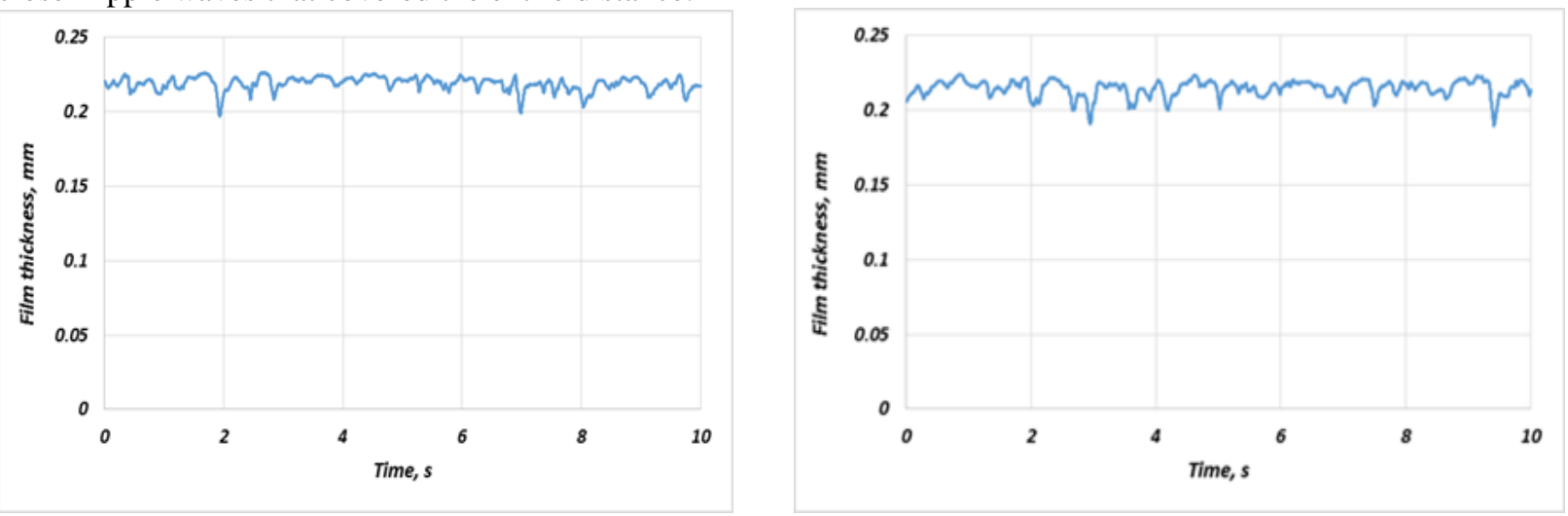

Fig. 14 - (a) Vsl=0.1892 m/s, Vsg=10.3927 m/s;

(b) $V s l=0.1805 \mathrm{~m} / \mathrm{s}, \mathrm{Vsg}=23.7259 \mathrm{~m} / \mathrm{s}$

\section{Conclusion}

The analyzed results of the two-phase (water/air) annular flow experiments, illustrated that annular flow could be attained from a superficial gas velocity of $8 \mathrm{~m} / \mathrm{s}$ in the pipe with $\mathrm{Vsl}=0.0903 \mathrm{~m} / \mathrm{s}$. The detailed annular flow behavior revealed that at low superficial gas and liquid velocity, annular flow behaves as annular-wavy flow in the pipe while at high superficial gas and liquid velocity, the tendency fades. In conclusion from the entire experimental results analyzed, more liquid film travels at the bottom of the pipe with thin wavy flow structures at the upper walls of the pipe depending on the liquid and gas velocity. 


\section{Acknowledgement}

The author is using this medium to express his gratitude to Cranfield University, Oil and Gas Engineering Centre, Bedfordshire, UK for making this research a reality through world class laboratory in the school. To appreciate one the best Principal Supervisor ever seen, Prof Falcone, G and her Co-Supervisor Dr. Liyun, for their good supervision. Special thanks also to the PSE Lab Manager, Mr Stan Collins and Shaun, the Technician for their support. And finally, a big thank you to TETFUND for the sponsorship and to my mentor/academic father, Prof., J. A. Ajienka,

\section{References}

[1] Osokogwu, Uche, (2020) "Evaluation of Wave Characteristics in Annular Flow in Horizontal pipes" International Journal of oil, Gas and Coal Engineering, Vol, 8. No. 1, pp. 1-9. doi: 10.11648/j.ogce.20200801.11

[2] Sergey, V. Alekseenko, Andrey, V. Cherdantsev, Mikhail, V. Cherdantsev, Sergey, V. Isaenkov, Sergey, M. Kharlamov and Dmitriy, M. Markovich (2014) "Formation of Disturbance Waves in Annular Gas-Liquid Flow" Kutateladze Institute of Thermophysics, Novosibirsk, Russia, Novosibirsk State University, Novosibirsk, Russia, 17th International Symposium on Applications of Laser Techniques to Fluid Mechanics, Lisbon, Portugal, 07-10 July, 2014

[3] Kesana, N.R., Throneberry, J.M., Mclaury, B.S., Shirazi, S.A and Rybicki, E.F,(2012) "Effect of Particle Size and Viscosity on Erosion in Annular and Slug Flow" Proceedings of the ASME 2012 International Mechanical Engineering Congress \& Exposition IMECE2012, November 9-15, 2012, Houston, Texas, USA

[4] Liang F., Song, L and Sun, Y (2015) "An Experimental Investigation of Phase Separation of Gas-Liquid TwoPhase Flow through a small break" college of Pipeline and Civil Engineering, China University of Petroleum, China, 'ELSEVIER, Chemical Engineering Research and Design, 102, pp 161-170, 22 June, 2015

[5] Zhang, H.Q., Wang, Q., Sarica, C and Brill, J.P (2003) "Unified Model for Gas-Liquid Pipe Flow via Slug Dynamics-part 1: Model development. J. Energy Resource Technology, 125(4), pp 266-273

[6] Setyawan, A., Indarto and Deendarlianto (2016) "The Effect of the Fluid Properties on the Wave Velocity and Wave Frequency of Gas-Liquid Annular Two-Phase Flow in a Horizontal Pipe" Experimental Thermal and Fluid Science, ELSEVIER, Vol. 71, pp 25-41

[7] Shedd, T. A., (2001) "Characteristics of the Liquid Film in Horizontal Two-Phase Flow", Thesis for Doctor of Phil. in Mechanical Engineering the University of Illinois at Urbana-Champaign

[8] Shoeb, A. and Clifford, G. (2005) "Wavelets; Multiscale Activity in Physiological Signals" J. Biomedical Signal and Image Processing Spring, 2005

[9] Taitel, Y and Dukler, A. E., (1976) "A Model for Predicting Flow Regime Transitions in Horizontal and Near Horizontal Gas-Liquid Flow” AICHE J., Vol. 22, pp. 47-55

[10] Paras, S. V and Karabelas, A. J (1991) "Droplet Entrainment and Deposition in Horizontal Annular Flow" Int. J. Multiphase Flow, Vol. 17, pp. 455-468

[11] Jones, O. C. and Zuber, N. (1975) "The Interrelation between Void Fraction Fluctuation and Flow Patterns in Two-Phase Flow" Int. J. Multiphase Flow, 2, pp. 273-306

[12] Vince, M. A. and Lahey, R. T. (1982) "On the Development of an Objective Flow Regime Indicator" Int. J. Multiphase Flow, 8, pp. 93-124

[13] McClusky, H. L., Holloway, M. V., Beasley, D. E. and Ochterbeck, J. M. (2002) "Continuous Wavelet Transforms of Instantaneous Wall Pressure in Slug and Churn Upward Gas-Liquid Flow" Journal of Fluid Engineering, Vol. 124, pp. 625-633 